brought to the sclera, lateral incisions could be made to enlarge the opening and so allow extraction, and previously inserted scleral sutures could be tied at once to minimise vitreous loss. The difficulty is vitreous loss before the parasite can be grasped, and by some such scheme as above this might be prevented.

The latest report May 1, 1945 : Right eye white. Vision $=$ good light perception. Tension normal. Projection doubtful from above.

Acknowledgment.-I wish to thank Colonel Rees, Officer Commanding British Military Hospital, and Lieut.-Col. B. W. Rycroft, Adviser in Ophthalmology, C.M.F., for permission to publish this case, and Sir. W. P. MacArthur and Dr. H. A. Baylis for identifying the specimen and giving me help in the preparation of this paper.

\title{
REFERENCES
}

Belding.-Text-book of Clinical Parasitology, 1942.

BRUCK.-Arch. of Ophthal., Vol. XII, p. 1042, 1935.

DUKE-ELdER.-Text-book of Ophthalmology, Vol. III, 1940.

Els̀irin IG.-Klin. Monatsbl. $f$. Augenheilk., Vol. LXXV, p. 130, 1925.

Griffith. - Trans. Ophthal. Soc U.K., Vol. XVII, p. 220, 1897.

LEBER.-Arch. f. Ophthal., Vol XXXII (I), p. $281,1886$.

MacArthur.-Roy. Soc. Trop. Med. and Hyg., p. 343, 1933.

Michail.-Ann. d'Ocul., Vol. CLXXII, p. 385, 1935.

TEale.-Roy. Lond. Ophthal. Hosp. Rpts., pp. 318-320, 1866.

\section{TANGENTIAL DISPLACEMENT OF THE IRIS IN CHRONIC GLAUCOMA*†}

BY

\author{
W. J. B. RIDDELL
}

GLASGOW

THE advanced atrophy of the iris stroma which is seen in patients suffering from chronic glaucoma of long standing is well known to all ophthalmologists. The condition with which this paper is concerned may be the early stage of this atrophy but it can be found in the early stages of the disease. In certain cases the normal radial arrangement of the iris stroma is replaced by a distribution running at a tangent to the pupillary margin. This change may involve a considerable segment, or even the whole iris. W.hen the condition is well marked the pupil appears to have rotated around its .own axis.

* A paper read at the Oxford Ophthalmological Congress, July, 1945. + Received for publication, July 14, 1945. 
glaucoma. My impression is that the condition is no more frequent in patients who have used miotics for a long time than in those who have had no such treatment.

The condition is shown diagrammatically in Fig. 1 in which the upper half indicates the normal radial arrangement and the lower half shows the tangential displacement. I have made several attempts to make photographs and considerable technical difficulties were encountered. A few of these were overcome by stereoscopic photographs, but in general the results were not very successful. In Fig. 2A a segment of a normal iris is shown above and that of a patient showing the alteration in iris pattern in . Fig. 2B.

In order to form an opinion regarding the incidence of this sign thirty-five patients with chronic glaucoma were examined consecutively for its presence or absence. The record was made prior to

This change in the appearance of the iris pattern has been familiar to me for a number of years, but it does not appear to be widely known that it may be seen in the early stages. Thus the routine clinical work. It is this practical point which I wish to stress rather than speculation upon the underlying mechanism. The sign may be present in quite early stages of the disease, but I have not seen this mentioned in the books frequently used by students and practitioners. As far as my observations have gone the appearance is only present in its permanent form in primary

FIG. 1.

\section{5}


operation in most cases. Those with only one eye were not included. The mean age of the patients was 62.1 years and there was no age difference between the sexes. There were seventeen men and eighteen women. The appearance was present in fourteen (five men and nine women) and was absent in twenty-one (twelve men and nine women) of the series of thirty-five. In two men and two women it was present in both eyes.

The information contributed by the seventy eyes of the thirtyfive patients was arranged in the manner shown in Fig. 3 . On the basis of visual acuity the material was divided into three groups;

VISION

\begin{tabular}{|c|c|c|c|c|}
\hline IRỊS & $6 / 12$ and better & $6 / 18$ to $6 / 60$ & $6 / 60$ and worse & \\
\hline Tangential & 6. & 4 & 8 & 18 \\
\hline \multirow[t]{2}{*}{ Normal } & 25 & 11 & 16 & 52 \\
\hline & 31. & 15 & 24 & 70 \\
\hline
\end{tabular}

FIG. 3.

those with recorded visual acuity of $6 / 12$ or better, those between $6 / 18$ and $6 / 60$ inclusive and those with less than $6 / 60$. This does not show any association between the presence or absence of tangential displacement and the condition of the patient, as judged by the visual acuity.

Among the six patients who showed iris pattern changes with good central vision, five had tension within normal limits, four had no cupping of the disc and three had no field defect. In only one patient was the evidence limited to the iris pattern change alone and she had well marked glaucoma in her other eye. In three of the patients the appearance of the iris provided corroborative evidence of real clinical value.

On the other hand when the ten patients were considered in whom the change was present in one eye but not in the other a tendency appeared for the iris pattern displacement to be associated with reduced acuity when the dividing line was $6 / 18$ and better. The distribution is shown in Fig. 4 and $I$ would accept these figures as being significant. That is to say that there is an association between change in iris pattern and poor central vision, although a few show the change only in the eye with the better acuity. 


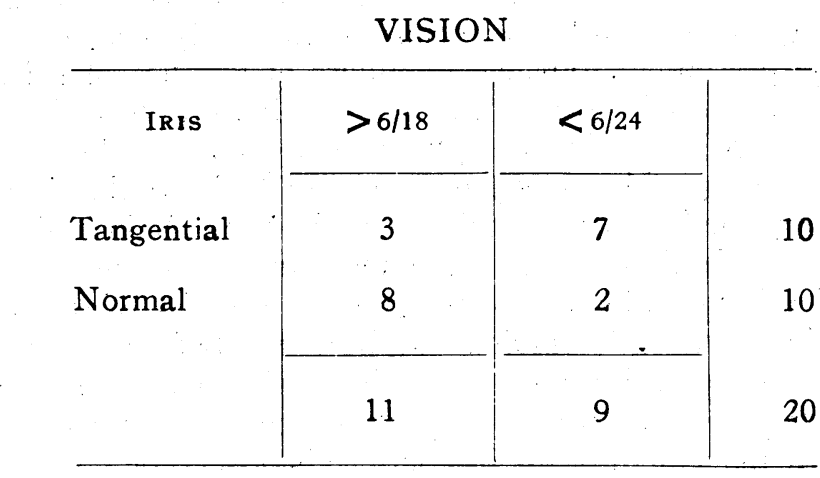

FIG. 4.

I have made no attempt to elaborate the matter by constructing tables showing the relationship to length of history, type of operation, visual fields or tonometer readings. Such would have tended to obscure my main point which is that a tangential displacement of the iris pattern may occur in chronic glaucoma in an eye which has good central vision and may be the better eye of the two. 'This sign may occur early in the disease and its presence is not confined to the advanced stages. This irregularity in appearance makes it the more necessary for us to be on the look-out. In fact this paper arose from my asserting that a patient was suffering from glaucoma on the visual evidence of one engorged anterior perforating ciliary vessel and tangential displacement of the pattern in one sector of the iris in one eye. Subsequent investigations on the usual lines confirmed my view.

The appearance has been seen by me in only one other condition and this may give a clue as to its origin in glaucoma. The patient was a man suffering from megalo-cornea and cataract. The iris pattern was generally atrophic in appearance, but no tangential displacement was seen until the pupil was dilated. The phenomenon was then clearly yisible and appeared to be due to atrophy or rigidity in one small area at the pupillary margin. With the slit-lamp one could see that the sphincter did not dilate in its entirety although the pupil dilated and was circular. It was as if a piece of elastic was formed into a band by the insertion of a small portion of string. Such a model would dilate into a complete circle with expansion of the rubber and the inelastic segment of string would conform to the circular pattern without itself expanding. If, to such a model, contractile radial trabeculae were attached it is obvious that tangential displacement would occur. So far I have' not secured any histological material at a sufficiently early stage to provide any evidence in support of this suggestion. 
Tangential displacement of the iris pattern is a common finding in chronic glaucoma and may occur in the early stages. It was found to be present in fourteen members of a series of thirty-five consecutive cases of chronic glaucoma. Although it is almost certainly a stage in the iris atrophy which occurs in the advanced condition, tabular evidence is presented which shows that it may be found in conjunction with good central vision. It is a sign subordinate to the findings of the tonometer and screen and certainly visual acuity is no index of the progressive severity of the disease. As inspection is usually carried out, however, before instrumental methods, the observation has a place in routine work. The serious nature of the eye condition may be suspected immediately if tangential displacement of the iris pattern is observed.

\title{
TEMPORARY CATARACTS IN DIABETES*
}

BY

\author{
R. D. LAWRENCE, M.D., F.R.C.P. \\ THE DIABETIC DEPARTMENT, \\ KING'S COLLEGE HOSITAL
}

THE very transient lens opacities that occur in intense dehydration of diabetic coma and last 1 or 2 days were recently described by Lawrence, Oakley and Barne (1942). Apart from such acute dehydration a few cases of longer lasting but temporary cataracts have been recorded. Nettleship (1885) described three patients in whom cataracts rapidly developed as diabetes grew worse and cleared when the treatment either abolished or diminished the urinary sugar. In one case " symmetrical nuclear cataracts," which prevented recognition of large objects, disappeared completely in two weeks and small print could be read again-this by diet and opium treatment which diminished the urinary sugar from extremely high to moderate amounts. The cases are not described in great detail and the metabolic details are scanty, but the facts are authentic and clear. Alt (1906) describes the eye changes in a young woman with neglected and progressively severe diabetes. One morning. while reading at 11 a.m. she was terrified by a sudden clouding of her right and later the left eye and at 5 p.m. Alt observed a large subcapsular opacity in the $R$. eye and radial streaks in the left. The strenuous diet she then submitted to reduced her sugar and in three weeks both lenses were quite clear

* Received for publication, November 24, 1945. 